\title{
Preface to the 5th International Slag Valorisation Symposium: From Fundamentals to Applications
}

\author{
Annelies Malfliet ${ }^{1} \cdot$ Yiannis Pontikes $^{1}$
}

Published online: 2 March 2018

(C) The Minerals, Metals \& Materials Society 2018

From April 3 to 5, 2017, the 5th International Slag Valorisation Symposium took place in Leuven, Belgium. Since the first Symposium in 2009, actors from both academia and industry have gathered in these Symposia to disseminate knowledge and to discuss the latest advances in the field of slag valorization. The subtheme for this Symposium was From Fundamentals to Applications. It covered the themes of clean slag production, metal recovery, slag solidification, and energy recuperation, next to slag-incorporating processes and products, such as new cements, aggregates, inorganic polymers, and alkali-activated binders. As sustainable materials management was a common thread in the past four Slag Valorisation Symposia, a specific session was dedicated to the principle of industrial ecology for high-temperature (metallurgical) residues as part of a circular economy. Selected contributions from this Symposium were invited in this thematic section of the Journal of Sustainable Metallurgy, as an extended and peer-reviewed version of the Symposium paper.

A first illustration of the development of fundamental knowledge related to slag valorization can be found in the work by Müller et al. [1] on modeling the viscosity of oxide slags. As changes in the viscosity of the slag can affect the mass transfer and flow in a metallurgical process, knowledge about and the ability to predict this property is important to simulate high-temperature processes. The group of Müller developed a new viscosity model to predict the viscosity of fully molten slags, which uses the same structural units as used in the thermodynamic description of the melt, thereby reflecting the relation between the viscosity and the structure of the slag. This is presented in their paper, together with the extension of the model taking into consideration the effect of crystallization

Annelies Malfliet

annelies.malfliet@kuleuven.be

1 Department of Materials Engineering, KU Leuven, 3001 Leuven, Belgium on both the change from a liquid to a dispersion and the change on the liquid composition.

The second example of fundamental research is shown in the paper by Bellemans et al. [2] who studied a particular case of metal losses in liquid slag. They considered that the adherence of metal droplets to solid particles can cause inadequate sedimentation behavior, which was experimentally studied by evaluating the $\mathrm{Cu}$ droplets and their attachment to spinel particles in a $\mathrm{Fe}-\mathrm{Si}-\mathrm{Al}-\mathrm{O}-$ based system. Supported by other works of the group using phase field modeling, this study draws conclusions on the origin of the attachment, which is the basis for understanding and eventually avoiding this mechanism and the associated production losses.

In the work of Nedeljkovic et al. [3], the carbonation of alkali-activated slag (AAS) pastes exposed to natural and accelerated conditions for up to 1 year was studied. Two aspects of carbonation mechanism were evaluated. The first was the potential carbonation of the main binding phases in finely powdered AAS pastes. The second was the reactivity and diffusivity of $\mathrm{CO}_{2}$ within the bulk AAS paste. It was found that powdered AAS was largely carbonated within 28 days, the main carbonation products being calcium carbonates. On the contrary, the bulk paste samples were highly resistant to carbonation, and the initial $\mathrm{pH}$ value and strength of the samples did not decrease under accelerated carbonation, nor was the mineralogy influenced by the two carbonation regimes studied. The authors conclude that the gel pores (in the range of $2-15 \mathrm{~nm}$ ) were dominant in the pastes, and that this dense microstructure was the main barrier for $\mathrm{CO}_{2}$ diffusion.

Mercado-Borrayo et al. [4] summarized and discussed the studies dealing with the use of metallurgical slag to remove inorganic, organic, and biological contaminants from water, originating from industrial activities or natural wells. The strategy of these studies, the suggested mechanisms of removal and the general trends in effectiveness of steel, iron, or copper slag as removing agent or catalyst are addressed. The authors come to the conclusion that most of 
the existing work is focused on finding the conditions to optimally remove the pollutant from the raw slag, but that less attention is given to other aspects such as to enhance the process by mechanical, chemical or thermal pretreatment of the slag material. Next to the limited studies dedicated to revealing the actual reaction mechanisms, Schouwenaars et al. indicated that very few assessments have been undertaken to quantify the economic viability, which explains at least in part why only few pilot- and plant-scale studies are known to the authors. Full exploitation of slags in this field requires further understanding and development of this emerging technology.

Liapis et al. [5] determined the technical, environmental, and economic benefits of using steel slag in five concrete applications, in their attempt to understand the requirements needed to make the step from laboratory scale to industrial application. Economic and environmental benefits of using slag as binder or aggregate in concrete are related to natural resource preservation, landfill reduction, and reduced greenhouse gas emissions through decreased cement consumption. Despite the potential for the use of steel slag in concrete infrastructure, it appears to be case dependent to which extent it is beneficial to use steel slag on the industrial scale. This illustrates that next to pure fundamental studies, works such as this of Liapis et al., which balance opportunities and possible barriers, are needed to direct the research efforts in the most favorable pathways to benefit from the qualities of steel slag in the most sustainable manner.

In the last work included in this thematic section, Friedrich et al. [6] present an overarching paper, bringing together fundamentals and industrial realization. The subject of the work is the submerged electric arc furnace for which the authors presented an overview of the principles behind the furnace and the recent innovations, together with examples of industrial installation and research in the field of red mud, copper slags, and lead slags. The work is an example of how the cooperation between researchers and engineers in industry has enabled the progress and optimization of an industrial process valuable for slag valorization. It is, in fact, acknowledged that important process improvements were realized by applying the full range of research, starting from the laboratory scale, then scaling-up to pilot scale, and concluding at an industrial scale.

The International Slag Valorisation Symposium has become one of the benchmarks in the domain of slag engineering and near zero-waste metallurgy, and the organizers have the willingness to continue organizing these Symposia. We all believe that the blending of highquality presentations and papers, ranging from fundamental research to real-life, full-scale applications, is contributing to the field and accelerates the transition toward more sustainable materials management.

\section{References}

1. Müller M, Seebold S, Wu G, Yazhenskikh E, Jantzen T, Hack K (2018) Experimental investigation and modeling of the viscosity of oxide slag systems. J Sustain Metall. https://doi.org/10.1007/ s40831-017-0144-2

2. Bellemans I, Cnockaert V, de Wilde E, Moelans N, Verbeken K (2018) Metal droplet entrainment by solid particles in slags: an experimental approach. J Sustain Metall. https://doi.org/10.1007/ s40831-017-0145-1

3. Nedeljkovic M, Zuo Y, Arbi K, Ye G (2018) Carbonation resistance of alkali-activated slag under natural and accelerated conditions. J Sustain Metall. https://doi.org/10.1007/s40831-0180166-4

4. Mercado-Borrayo BM, González-Chávez JL, Ramírez-Zamora RM, Schouwenaars R (2018) Valorization of metallurgical slag for the treatment of water pollution: an emerging technology for resource conservation and re-utilization. J Sustain Metall. https:// doi.org/10.1007/s40831-018-0158-4

5. Liapis A, Anastasiou EK, Papachristoforou M, Papayianni I (2018) Feasibility study and criteria for EAF slag utilization in concrete products. J Sustain Metall. https://doi.org/10.1007/s40831-0170152-2

6. Friedrich B, Kalisch M, Friedmann D, Degel R, Kaußen F, Böhlke J (2018) The submerged arc furnace (SAF): state-of-the-art metal recovery from nonferrous slags. J Sustain Metall. https://doi.org/ 10.1007/s40831-017-0153-1 